\title{
Determination of Economic Systems Behaviour under Uncertainty
}

\author{
A. I. Serguieva \\ Department of Systems and Control, Technical University-Sofia, 1756 Sofia, BULGARIA
}

\begin{abstract}
I}$
This paper discuses systems of difference equations with fuzzy parameters and presents some solution procedures with the purpose to study the dynamic behaviour of economic systems in case of uncertainty. The trajectories of the endogenous variables are evaluated firstly at contiguous moments of time, and then, simultaneously. The relations between different solutions are shown. The author also consider essential to provide an algorithm for computing the exact $\alpha$-cuts of the obtained solutions.
\end{abstract}

Keywords: Econometrics; dynamics; systems of difference equations; nonlinear programming.

\section{1: Introduction}

An essential number of economic models, especially macroeconomic models, represent systems of difference equations $[9,10,18,19]$. They are dynamic models and allow an examination of the economic systems development (in contrast to the static models and comparative static models). An economic model includes endogenous variables, control (policy) variables, and exogenous (uncontrollable) variables. Having the values of the exogenous variables available and giving some values to the control variables in an simultaneous difference equations model we will be able to obtain the trajectories of the endogenous variables and study the economic system behaviour.

It is well known that the macroeconomic models only approximate to the complex interrelations between a countless number of indices characterising the national economy. Within limits, it is also true for microeconomic models. Therefore, it is reasonable to assume that the models are uncertain. There are a lot of methods for uncertainty modelling. In this paper we suggest that the parameters of an economic model are

\footnotetext{
*The author is indebted to Prof. J. Buckley for supplying her with most of the necessary literature.

'This work was partially supported by the National fund 'Scientific Research' under Grant No НИ-ТН-478/94.
}

uncertain use real fuzzy numbers with triangular membership functions instead of the crisp parameters or real-valued fuzzy variables with triangular possibility distributions, whose values are the possible parameters. The main result of these methods is that we can determine all trajectories of the endogenous variables using values of the parameters all at the same level of uncertainty. As the fuzzy analysis is essentially plural interval analysis, we believe it will be useful for the economic analists. We also provide a more informative crisp solution (than the ordinary crisp solution) for each level of uncertainty, in case the economic system authorities have no enough time to consider all possibilities.

Consequently, the problem of determination of economic systems behaviour under uncertainty turns into a problem of solving systems of difference equations with fuzzy parameters. Single equations (linear, quadratic or non-linear) with fuzzy parameters are discussed in $[2,3,6,11,12,15]$. In $[7,14,17]$ single fuzzy differential equations are considered, as well. There have been also proposed some methods for solving systems of linear fuzzy equations $[4,6]$, systems of non-linear fuzzy equations [8], and in $[5,6]$ the author solves an exemplary system of two fuzzy differential equations. In this paper we extend the implementation of both the solution procedure based on the united extension and the solution procedure based on the possibility theory to the case of systems of fuzzy difference equations. First, we evaluate the values of the endogenous variables consecutively (at contiguous moments of time), and then, consider a simultaneous evaluation of the whole trajectory. We also apply the nonlinear programming to compute the exact solutions. In [13] the author uses the nonlinear programming to find the exact interval determinant of an interval matrix. In this paper it is applied with the purpose the exact $\alpha$-cuts of the solution to be find.

\section{2: Evaluating fuzzy trajectories 2.1: Problem statement}


The structural form for an economic model consisting of a system of difference equations can be written as:

$$
\begin{aligned}
y_{t}= & A_{0} y_{t}+A_{1} y_{t-1}+\ldots+A_{k} y_{t-k}+B_{1} u_{t-1}+\ldots+ \\
& +B_{M} u_{t-M}+C_{1} z_{t-1}+\ldots+C_{L} z_{t-L},
\end{aligned}
$$

where $y_{t-k}$ are $n_{1}$-vectors of endogenous variables appearing with lag $k=\overline{0, K}, u_{t-m}$ are $r_{1}$-vectors of control variables appearing with $\operatorname{lag} m=\overrightarrow{1, M}$, and $z_{t \cdot 1}$ are $s_{1}-$ vectors of exogenous variables appearing with lag $\mathrm{l}=\overline{1, L} \cdot \mathrm{A}_{\mathrm{k}}$ are $\mathrm{n}_{1} \times n_{1}$ matrices, $\mathrm{B}_{\mathrm{m}}$ are $\mathrm{n}_{1} \mathrm{xr}_{1}$ matrices, and $C_{1}$ are $n_{1} x_{1}$ matrices. The problem can be formulated as follows. In model (1) we know the crisp trajectories of the exogenous variables on interval $[-\mathrm{L}, \mathrm{T}]$, the crisp trajectories of the endogenous variables on interval
$[-\mathrm{K}, 0]$, and the trajectories of the control variables on interval $[-\mathrm{M},-1]$. Giving some values to the control variables at moments $t=0, \ldots, T-1$, we will consecutively obtain the values of the endogenous variables at moments $\mathrm{t}=1, \ldots, \mathrm{t}=\mathrm{T}$.

We can re-specify model (1) as a quasi first-order system. $[10,16]$ This means defining new variables to replace those variables that appeared in the model with lags greater than one period and adding their definitional equations to the model. The new vectors are:

$$
\begin{aligned}
& \mathrm{y} 1_{\mathrm{t}}=\mathrm{y}_{\mathrm{t}-1}, \mathrm{y} 2_{\mathrm{t}}=\mathrm{y}_{\mathrm{t}-2}, \ldots, \mathrm{y}(\mathrm{K}-1)_{\mathrm{t}}=\mathrm{y}_{\mathrm{t}-\mathrm{K}+1}, \mathrm{u} 1_{\mathrm{t}}=\mathrm{u}_{\mathrm{t}-1}, \ldots, \\
& \mathrm{u}(\mathrm{M}-1)_{\mathrm{t}}=\mathrm{u}_{\mathrm{t}-\mathrm{M}+1}, \mathrm{z} 1_{\mathrm{t}}=\mathrm{z}_{\mathrm{t}-1}, \ldots, \mathrm{z}(\mathrm{L}-1)_{\mathrm{t}}=\mathrm{z}_{\mathrm{t}-\mathrm{L}+1} .
\end{aligned}
$$

Now the model can be re-written as:

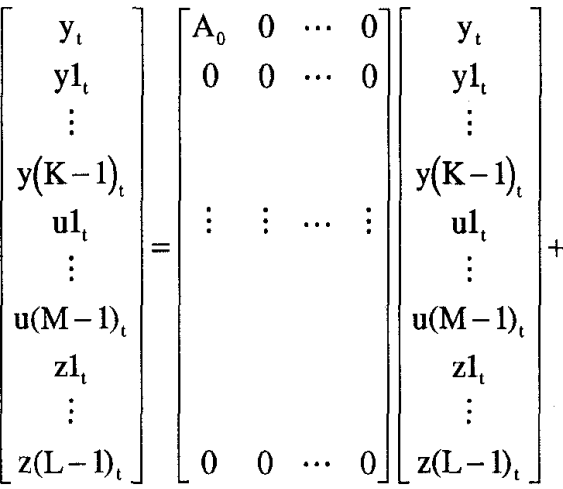

$$
+\left[\begin{array}{ccccccccccc}
\mathrm{A}_{1} & \mathrm{~A}_{2} & \cdots & \mathrm{A}_{\mathrm{K}-1} & \mathrm{~A}_{\mathrm{K}} & \mathrm{B}_{2} & \cdots & \mathrm{B}_{\mathrm{M}-1} & \mathrm{~B}_{\mathrm{M}} & \mathrm{C}_{2} & \cdots \\
\mathrm{I} & 0 & \cdots & 0 & 0 & 0 & \cdots & 0 & 0 & 0 & \cdots \\
0 & \mathrm{I} & \cdots & 0 & 0 & 0 & \cdots & 0 & 0 & 0 & \cdots \\
\vdots & \vdots & \cdots & \vdots & \vdots & \vdots & \cdots & \vdots & \vdots & \vdots & \cdots \\
0 & 0 & \cdots & \mathrm{I} & 0 & 0 & \cdots & 0 & 0 & 0 & \cdots \\
0 & 0 & \cdots & 0 & 0 & 0 & \cdots & 0 & 0 & 0 & \cdots \\
0 & 0 & \cdots & 0 & 0 & \mathrm{I} & \cdots & 0 & 0 & 0 & \cdots \\
\vdots & \vdots & \cdots & \vdots & \vdots & \vdots & \cdots & \vdots & \vdots & \vdots & \cdots \\
0 & 0 & \cdots & 0 & 0 & 0 & \cdots & \mathrm{I} & 0 & 0 & \cdots \\
0 & 0 & \cdots & 0 & 0 & 0 & \cdots & 0 & 0 & 0 & \cdots \\
0 & 0 & \cdots & 0 & 0 & 0 & \cdots & 0 & 0 & \mathrm{I} & \cdots \\
\vdots & \vdots & \cdots & \vdots & \vdots & \vdots & \cdots & \vdots & \vdots & \vdots & \cdots \\
0 & 0 & \cdots & 0 & 0 & 0 & \cdots & 0 & 0 & 0 & \cdots
\end{array}\right.
$$

If we define:

$$
\mathrm{x}_{\mathrm{t}}=\left[\mathrm{y}_{\mathrm{t}} \ldots \mathrm{z}(\mathrm{L}-1)_{\mathrm{t}}\right]^{\prime}
$$

and label appropriately the matrices in (3), we will obtain the following equation:

$$
x_{t}=D_{0} x_{t}+D_{1} x_{t-1}+D_{2} u_{t-1}+D_{3} z_{t-1} \text {. }
$$

Supposing $\left(\mathrm{I}-\mathrm{D}_{0}\right)^{-1}$ exists, the (5) can be re-written as:

$$
\begin{aligned}
x_{t} & =\left(I-D_{0}\right)^{-1} D_{1} x_{t-1}+\left(I-D_{0}\right)^{-1} D_{2} u_{t-1}+\left(I-D_{0}\right)^{-1} D_{3} z_{t-1}= \\
& =A x_{t-1}+B u_{t-1}+C z_{t-1},
\end{aligned}
$$

$$
\left.\begin{array}{ccc}
\cdots & \mathrm{C}_{\mathrm{L}-1} & \mathrm{C}_{\mathrm{L}} \\
\cdots & 0 & 0 \\
\cdots & 0 & 0 \\
\cdots & \vdots & \vdots \\
\cdots & 0 & 0 \\
\cdots & 0 & 0 \\
\cdots & 0 & 0 \\
\cdots & \vdots & \vdots \\
\cdots & 0 & 0 \\
\cdots & 0 & 0 \\
\cdots & 0 & 0 \\
\cdots & \vdots & \vdots \\
\cdots & \mathrm{I} & 0
\end{array}\right]\left[\begin{array}{c}
\mathrm{y}_{\mathrm{t}-1} \\
\mathrm{y}_{\mathrm{t}=1} \\
\mathrm{y}_{\mathrm{t}-1} \\
\vdots \\
\mathrm{y}(\mathrm{K}-1)_{\mathrm{t}-1} \\
\mathrm{u} 2_{\mathrm{t}-1} \\
\vdots \\
\mathrm{u}(\mathrm{M}-1)_{\mathrm{t}-1} \\
\mathrm{zl}_{\mathrm{t}-1} \\
\mathrm{z} 2_{\mathrm{t}-2} \\
\vdots \\
\mathrm{z}(\mathrm{L}-1)_{\mathrm{t}-1}
\end{array}\right]+\left[\begin{array}{c}
\mathrm{B}_{1} \\
0 \\
0 \\
\vdots \\
0 \\
\mathrm{I} \\
0 \\
\vdots \\
0 \\
0 \\
0 \\
\vdots \\
0
\end{array}\right] \mathrm{u}_{\mathrm{t}-1}+\left[\begin{array}{c}
\mathrm{C}_{1} \\
0 \\
0 \\
\vdots \\
0 \\
0 \\
\vdots \\
0 \\
\mathrm{I} \\
0 \\
\vdots \\
0
\end{array}\right] \mathrm{z}_{\mathrm{t}-1}
$$
$\mathrm{n}=\mathrm{Kn} \mathrm{n}_{1}+(\mathrm{M}-1) \mathrm{r}_{1}+(\mathrm{L}-1) \mathrm{s}_{1}$, the dimension of matrix $\mathrm{A}$ is $\mathrm{nxn}, \mathrm{B}$ is an $\mathrm{nxr_{1 }}$ matrix, and $\mathrm{C}$ is an $\mathrm{nxs}_{1}$ matrix. Practically, $n<<K n_{1}+(M-1) r_{1}+(L-1) s_{1}$, because some of the endogenous variables might appear with maximum lags less than $\mathrm{K}$, some of the control variables might appear with maximum lags less than $M$, and some of the exogenous variables with maximum lags less than $\mathrm{L}$. The solution of the quasi first-order system (6) is: where the dimension of vector $x_{t}$ is 


$$
x_{i}=A^{\prime} x_{0}+\sum_{i=0}^{t-1} A^{t-j-1}\left(B u_{i}+C z_{i}\right) .
$$

Now, using model (7), we can give an equivalent formulation of the problem. The initial value of vector $x_{t}$, $x_{0}$, and the trajectory of vector $z_{i}$ on interval $[0, T-1]$ are given, and the trajectory of vector $x_{t}$ on interval $[1, T]$ is to be find. Various economic policies (trajectories of the control variables) can be examine to learn more about the dynamic behaviour of the system. An advantage of model (7) is that it allows a simultaneous evaluation of the whole trajectory of the endogenous variables as well as determination of a separate value of the endogenous vector, when we are interested only in a forecast at a definite future moment.

\section{2: Introduction of the necessary notations}

We want to present and solve the problem in case of uncertainty, which requires firstly to introduce some notations. Let $r=\left[r_{1} \ldots r_{p}\right]^{\prime}$ be a p-vector of the non-zero elements of matrices $A_{0}, \ldots, A_{k}, B_{1}, \ldots, B_{M}, C_{1}, \ldots, C_{L}$. We will denote the real fuzzy numbers to be substituted for the parameters $r_{i}$ of the model as $\tilde{R}, i=\overline{1, p}$, and $\tilde{S}_{i j}$, $j=\overline{1, n_{1}}, t=\overline{1, T}$, will represent the obtained real fuzzy numbers for solutions. By analogy, the real-valued fuzzy variables whose values are to be parameters will be denoted as $\breve{R}_{i}$, and $\breve{S}_{i j}$ will represent the real fuzzy variables whose values are possible solutions. For simplicity, we employ triangular membership functions for fuzzy numbers $\tilde{R}_{i}$ and triangular possible distributions for fuzzy variables $\breve{R}_{\mathrm{i}}$. We also choose

$$
\operatorname{Poss}\left[\breve{R}_{i}=r_{i}\right]=\mu\left(r_{i} / \widetilde{R}_{i}\right)=\left(r_{i 1} / r_{i 2} / r_{i 3}\right) \text {, }
$$

The $\tilde{R}_{i}(\alpha)$ will be called an $\alpha$-cut of $\tilde{R}_{i}$ if $\tilde{R}_{i}(\alpha)=\left[\underline{r}_{i}(\alpha), \bar{r}_{i}(\alpha)\right]=\left\{r_{i} \mid \mu\left(r_{i} \mid \tilde{R}_{i}\right) \geq \alpha\right\}$ for $0<\alpha \leq 1$ and $\tilde{R}_{i}(0)$ is the closure of the union of $\tilde{R}_{i}(\alpha), 0<\alpha \leq 1$. If interrelation (8) holds, then

$$
\tilde{\mathrm{R}}_{i}(\alpha)=\left[\underline{\mathrm{r}_{1}(\alpha)}, \overline{\mathrm{r}_{1}(\alpha)}\right]=\left\{\mathrm{r}_{\mathrm{j}} \mathrm{P} \operatorname{Poss}\left[\breve{\mathrm{R}}_{\mathrm{i}}=\mathrm{r}_{\mathrm{i}}\right] \geq \alpha\right\}, 0 \leq \alpha \leq 1 .
$$

We adopt the definition of a real fuzzy number given in [1] and definition of a fuzzy vector given in [8]. If $\widetilde{\mathrm{S}}_{\mathrm{t}}$, $j=\overline{1, n_{1}}$, are real fuzzy numbers, then $\tilde{s}_{v}$, whose membership function is $\mu\left(y_{t} \mid \tilde{S}_{t}\right)=\min _{1 \leq j \leq n_{1}}\left\{\mu\left(y_{i j} \mid \tilde{S}_{t i}\right)\right\}$, is a fuzzy vector. In contrast, if $\widetilde{S}_{t}$ is a fuzzy vector, then its marginals $\tilde{S}_{i j}$, defined by their membership functions

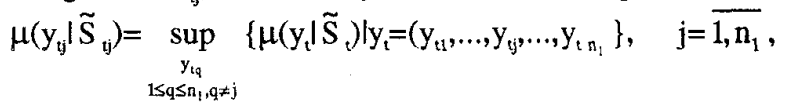
are real fuzzy numbers.
Finally, we will introduce the Cartesian product

$$
\tilde{\mathrm{R}}(\alpha)=\prod_{\mathrm{i}=1}^{\mathrm{p}} \tilde{\mathrm{R}}_{\mathrm{i}}(\alpha), 0 \leq \alpha \leq 1 .
$$

and the joint possibility distribution

$$
\pi_{\mathrm{r}}=\min _{\text {Lisp }}\left\{\mu\left(\mathrm{r}_{\mathrm{i}} \mid \tilde{\mathrm{R}}_{\mathrm{i}}\right)\right\} \text {. }
$$

In the next subsection we will find $\tilde{S}_{t}(\alpha)$ using $\tilde{R}(\alpha)$, which means to find all solutions for $y_{t}$ using all the values of $r_{i}$ at the same level of uncertainty, as the last ones belong to the sets $\left\{\mathbf{r}_{i} \mid \operatorname{Poss}\left[\breve{R}_{j}=r_{i}\right] \geq \alpha\right\}$.

\section{3: Solutions}

Supposing that both $\left(\mathrm{I}-\mathrm{D}_{0}\right)^{-1}$ and $\left(\mathrm{I}-\mathrm{A}_{0}\right)^{-1}$ exist for all $r_{i} \in \tilde{R}_{i}(0), i=\overline{1, p_{0}}, p_{0}<p$, where $\left(r_{1}, \ldots, r_{i p_{0}}\right)$ are elements of $\mathrm{A}_{0}$, we give eight solutions for the fuzzy trajectories of the endogenous variables and compare them. Then, for each level of uncertainty we propose a crisp solution which contains part of the information about the fuzzy solution, and consequently is more possible than the ordinary crisp solution.

First, we will substitute fuzzy numbers $\widetilde{R}_{i}$ for $r_{i}$ in models (1) and (7). In the fuzzified version of equation (1), the solution at moment $\geq 2$ depends on both the fuzzy parameters and the solutions at moments $t-K, \ldots, t-1$ for $\mathrm{t}>\mathrm{K}$ (solutions at moments $1, \ldots, \mathrm{t}-1$ for $\mathrm{t} \leq \mathrm{K}$ ). Therefore, we can write

$$
\begin{gathered}
y_{t}=\left\{\begin{array}{l}
f_{t_{i j}}(r), j=\overline{1, n_{1}}, t=1 \\
f_{t_{j}}\left(r, y_{1}, \ldots, y_{t-1}\right), j=\overline{1, n_{1}, t}=\overline{2, K} \\
f_{t_{j}}\left(r, y_{t-K}, \ldots, y_{t-1}\right), j=\overline{1, n_{1}}, t=\overline{K+1, T}
\end{array}\right. \\
y_{t}=\left\{\begin{array}{l}
F_{t}(r), F_{t}=\left[f_{t 1} \ldots f_{t t_{1}}\right]^{\prime}, t=1 \\
F_{t}\left(r, y_{1}, \ldots, y_{t-1}\right), F_{t}=\left[f_{t} \ldots f_{t n_{1}}\right]^{\prime}, t=\overline{2, K} \\
F_{t}\left(r, y_{t-K}, \ldots, y_{t-1}\right), F_{t}=\left[f_{t 1} \ldots f_{t_{1}}\right]^{\prime}, t=\overline{K+1, T}
\end{array}\right.
\end{gathered}
$$

From equation (7) it follows that

$$
\begin{aligned}
& x_{\mathrm{t}}=\mathrm{g}_{\mathrm{t}}(\mathrm{r}), \mathrm{j}=\overline{1, \mathrm{n}}, \\
& \mathrm{x}_{\mathrm{t}}=\mathrm{G}_{\mathrm{t}}(\mathrm{r}), \mathrm{G}_{\mathrm{t}}=\left[\mathrm{g}_{\mathrm{t}}, \ldots, \mathrm{g}_{\mathrm{ta}}\right]^{\prime} .
\end{aligned}
$$

As the first $n_{1}$ elements of vector $x_{t}$ correspond to vector $\mathrm{y}_{\mathrm{t}}$, it is true that

$$
\begin{aligned}
& y_{\mathrm{y}}=\mathrm{g}_{\mathrm{y}}(\mathrm{r}), \mathrm{j}=\overline{1, \mathrm{n}_{1}}, \\
& \mathrm{y}_{\mathrm{t}}=\mathrm{G}_{\mathrm{yt}}(\mathrm{r}), \mathrm{G}_{\mathrm{y}}=\left[\mathrm{g}_{\mathrm{u}}, \ldots, \mathrm{g}_{\mathrm{t}_{\mathrm{t}}}\right]^{\prime} .
\end{aligned}
$$

Let $\tilde{S} 1_{1,}, \tilde{S} 2_{t}, \quad \tilde{S} 3_{t j}$ and $\tilde{S} 4_{t}$ be the united extension solutions of fizzified equations (11a), (11b), (13a) and (13b), respectively. Form Cartesian products:

$$
\begin{aligned}
& \Theta 1_{t}(\alpha)=\widetilde{R}(\alpha) \times \widetilde{S} 1_{t-K, 1}(\alpha) \times \tilde{S} 1_{t-K, n_{1}}(\alpha) x \ldots \times \tilde{S} 1_{t-1, n_{t}}(\alpha),(14 a) \\
& \Theta 2_{t}(\alpha)=\tilde{R}(\alpha) \times \widetilde{S} 2_{t \cdot K}(\alpha) \times \ldots \times \widetilde{S} 2_{t \cdot 1}(\alpha) \text {, }
\end{aligned}
$$


$0 \leq \alpha \leq 1$, where $\tilde{\mathrm{S}} 1_{\mathrm{y}}(\alpha)=\mathrm{y}_{\mathrm{ti}}$ and $\tilde{\mathrm{S}} 2_{\mathrm{t}}(\alpha)=\mathrm{y}_{\mathrm{t}}$ for $\mathrm{t}<1$, and define solutions $\tilde{\mathrm{S}} 1_{\mathrm{it}}, \quad \tilde{\mathrm{S}} 2_{\mathrm{t}}, \quad \tilde{\mathrm{S}} 3_{\mathrm{tj}}$ and $\tilde{\mathrm{S}} 4_{\mathrm{t}}$ by their membership functions

$$
\begin{aligned}
& \mu\left(\mathrm{y}_{\mathrm{t}} \mid \widetilde{\mathrm{S}} 1_{\mathrm{ig}}\right)=\sup \left\{\alpha \mid \mathrm{y}_{\mathrm{tj}} \in \widetilde{\mathrm{S}} 1_{\mathrm{v}}(\alpha)\right\}, \mathrm{j}=\overline{1, \mathrm{n}_{1}} \text {, where } \\
& \widetilde{S} 1_{t j}(\alpha)=\left\{f_{i j} \mid\left(r, y_{t-1,1}, \ldots, y_{t-n_{n}, n_{1}}\right) \in \Theta 1_{i}(\alpha)\right\}, 0 \leq \alpha \leq 1, j=\overline{1, n_{1}},(15 a) \\
& \mu\left(y_{t} \mid \tilde{S} 2_{v}\right)=\sup \left\{\alpha \mid y_{t} \in \tilde{S} 2_{t}(\alpha)\right\} \text {, where } \\
& \tilde{S} 2_{t}(\alpha)=\left\{F_{t}\left(r, y_{t-1}, \ldots, y_{t-k}\right) \in \Theta 2_{t}(\alpha)\right\}, 0 \leq \alpha \leq 1 \text {, } \\
& \mu\left(y_{\mathrm{t}} \mid \tilde{\mathrm{S}} 3_{\mathrm{t}}\right)=\sup \left\{\alpha \mid \mathrm{y}_{\mathrm{tj}} \in \tilde{\mathrm{S}} 3_{\mathrm{t}}(\alpha)\right\}, \mathrm{j}=\overline{1, \mathrm{n}_{1}} \text {, where } \\
& \widetilde{S} 3_{v}(\alpha)=\left\{g_{y j}(r) \mid r \in \widetilde{R}(\alpha)\right\}, 0 \leq \alpha \leq 1, j=\overline{1, n_{1}} \text {, } \\
& \mu\left(y_{\imath} \mid \tilde{S} 4_{\imath}\right)=\sup \left\{\alpha \mid y_{t} \in \tilde{S} 4_{\imath}(\alpha)\right\} \text {, where } \\
& \widetilde{S} 4_{\imath}(\alpha)=\left\{G_{y y}(r) \mid r \in \tilde{R}(\alpha)\right\}, 0 \leq \alpha \leq 1 \text {. }
\end{aligned}
$$

As the function $G_{y t}$ is continuous and $\tilde{R}_{i}$ are triangular fuzzy numbers, it can be easily proved that $\widetilde{S} 4_{t}$ is a fuzzy vector. It is also true that $\tilde{S} 4_{i j}$ is a fuzzy number with membership function

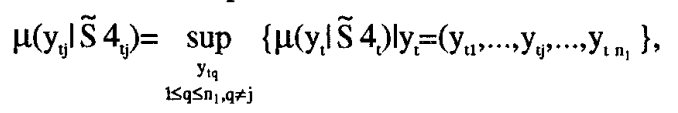

$\mathrm{j}=\overline{1, \mathrm{n}_{1}}$. It is obvious that $\widetilde{\mathrm{S}} 3_{\mathrm{ij}}$ is a real fuzzy number and $\tilde{\mathrm{S}} 3_{\mathrm{t}}$ is a fuzzy vector with membership function

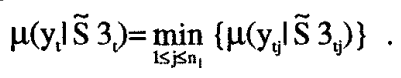

If we evaluate $\tilde{S} 1_{t, j}\left(\tilde{S} 2_{t}\right)$ considering $\tilde{S} 1_{t \cdot-\mathrm{j},}, \ldots, \tilde{S} 1_{t-1, j}$ $\left(\tilde{S} 2_{\mathrm{t}-\mathrm{K}}, \ldots, \tilde{\mathrm{S}} 2_{\mathrm{t}-\mathrm{K}}\right.$ ) given, then it can be proved that $\tilde{\mathrm{S}} 1_{\mathrm{i}}$ is a fuzzy number ( $\widetilde{\mathrm{S}} 2_{\mathrm{t}}$ is a fuzzy vector). Also, the $\tilde{\mathrm{S}} 1_{\mathrm{t}}$ is a fuzzy vector with membership function

$$
\mu\left(\mathrm{y}_{\mathrm{t}} l \tilde{\mathrm{S}} 1_{\nu}\right)=\min _{1 \leq j \leq n_{1}}\left\{\mu\left(\mathrm{y}_{\mathrm{t}} \mid \tilde{\mathrm{S}} 1_{\mathrm{t}}\right)\right\} .
$$

and $\tilde{s} 2_{i j}, j=\overline{1, n_{1}}$, are fuzzy numbers with membership functions

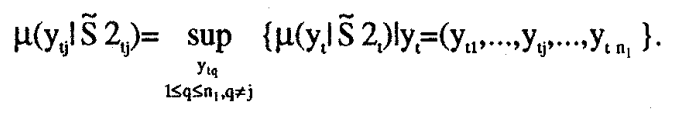

As $\widetilde{S} 1_{\mathrm{ij}}$ and $\widetilde{\mathrm{S}} 2_{\mathrm{t}}$ are evaluated consecutively, and $\widetilde{\mathrm{S}} 3_{\mathrm{t}}$ and $\widetilde{S} 4$ are evaluated simultaneously, it is logical to obtain that $\tilde{\mathrm{S}} 1_{\mathrm{ij}} \geq \tilde{\mathrm{S}} 3_{\mathrm{t} j}, \tilde{\mathrm{S}} 1_{\mathrm{t}} \geq \tilde{\mathrm{S}} 3_{\mathrm{t}}, \tilde{\mathrm{S}} 2_{\mathrm{t}} \geq \tilde{\mathrm{S}} 4_{\mathrm{t}}$, and $\tilde{\mathrm{S}} 2_{\mathrm{t}} \geq \tilde{\mathrm{S}} 4_{\mathrm{t} j}$. Furthermore, as $\tilde{S} 1_{i j}\left(\tilde{S} 3_{i j}\right)$ are usually interactive, the relation $\tilde{S} 1_{t} \geq \tilde{S} 2_{t}\left(\tilde{S} 3_{t} \geq \tilde{S} 4_{t}\right)$ holds.

Now model the uncertainty by real-valued fuzzy variables $\breve{R}_{i}$ whose values are to be parameters $r_{i}$. Let $\breve{S} 5_{1 j}, \breve{S} \sigma_{t}, \breve{S} 7_{t ;}$, and $\breve{S} 8_{t}$ be fuzzy variables whose values are possible solutions for $y_{t j}$ to equation (11a), for $y_{t}$ to equation (11b), $y_{t}$ to equation (13a), and $y_{t}$ to equation (13b), respectively. Then, form the joint possibility distributions

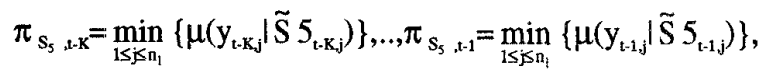

$$
\begin{aligned}
& \pi_{s_{S}}=\min \left\{\pi_{r}, \pi_{s_{5}, t-k}, \ldots, \pi_{s_{5}, k-1}\right\}, \\
& \pi_{\mathrm{S}_{\mathrm{\sigma}}}=\min \left\{\pi_{\mathrm{t}}, \mu\left(\mathrm{y}_{\mathrm{t}-\mathrm{L}} \mid \tilde{\mathrm{S}} \sigma_{\mathrm{t}-\mathrm{K}}\right), \ldots, \mu\left(\mathrm{y}_{\mathrm{t}-\mathrm{t}} \mid \tilde{\mathrm{S}} \sigma_{\mathrm{t}-1}\right)\right\},
\end{aligned}
$$

where

$$
\begin{aligned}
& \mu\left(\mathrm{y}_{t \cdot \mathrm{K}_{\mathrm{j}}} \mid \widetilde{\mathrm{S}} 5_{\mathrm{t}_{\mathrm{K} \mathrm{j}}}\right)=\operatorname{Poss}\left[\widetilde{\mathrm{S}} 5_{\mathrm{t} \cdot \mathrm{K} \mathrm{j}}=\mathrm{y}_{\mathrm{t} \cdot \mathrm{K} \mathrm{j}}\right], \ldots, \\
& \mu\left(\mathrm{y}_{\mathrm{t}-\mathrm{j}} \mid \tilde{\mathrm{S}} 5_{\mathrm{t}-1, \mathrm{j}}\right)=\operatorname{Poss}\left[\breve{S} 5_{\mathrm{t}-1, j}=y_{t-1, j}\right], j=\overline{1, n_{1}} \text {, } \\
& \mu\left(\mathrm{y}_{\mathrm{t} \cdot \mathrm{K}} \mid \tilde{\mathrm{S}} \sigma_{\mathrm{t} \cdot \mathrm{K}}\right)=\operatorname{Poss}\left[\breve{\mathrm{S}} \sigma_{\mathrm{t}-\mathrm{K}}=\mathrm{y}_{\mathrm{t} \cdot \mathrm{K}}\right], \ldots \text {, } \\
& \mu\left(\mathrm{y}_{\mathrm{t}: 1}, \tilde{\mathrm{S}} \sigma_{\mathrm{t}: \mathrm{t}}\right)=\operatorname{Poss}\left[\breve{\mathrm{S}} \sigma_{\mathrm{t} \cdot \mathrm{t}}=\mathrm{y}_{\mathrm{t}-1}\right] \text {, }
\end{aligned}
$$

and define

$$
\begin{aligned}
& \operatorname{Poss}\left[\breve{S} 5_{\mathrm{v}}=\mathrm{y}_{\mathrm{t}}\right]=\sup \left\{\pi_{\mathrm{s}_{\mathrm{s}}} \mid(11 \mathrm{a}) \text { hold }\right\}, \\
& \operatorname{Poss}\left[\breve{S} \sigma_{\mathrm{t}}=\mathrm{y}_{\mathrm{t}}\right]=\sup \left\{\pi_{\mathrm{S}_{\mathrm{f}}} \mid(11 \mathrm{~b}) \text { hold }\right\}, \\
& \operatorname{Poss}\left[\breve{S} 7_{\mathrm{t}}=\mathrm{y}_{\mathrm{t}}\right]=\sup \left\{\pi_{\mathrm{r}} \mid(13 \mathrm{a}) \text { hold }\right\}, \\
& \operatorname{Poss}\left[\breve{S} \delta_{\mathrm{t}}=\mathrm{y}_{\mathrm{t}}\right]=\sup \left\{\pi_{\mathrm{f}} \mid(13 \mathrm{~b}) \text { hold }\right\} .
\end{aligned}
$$

It is not difficult to prove that

$$
\begin{aligned}
& \operatorname{Poss}\left[\breve{S} 5_{\mathrm{ij}}=\mathrm{y}_{\mathrm{ij}}\right]=\mu\left(\mathrm{y}_{\mathrm{tj}} \tilde{\mathrm{S}} 1_{\mathrm{iv}}\right) \text {, } \\
& \operatorname{Poss}\left[\breve{S} \epsilon_{i}=y_{t}\right]=\mu\left(y_{t} \mid \widetilde{S} 2_{l}\right) \text {, } \\
& \operatorname{Poss}\left[\check{S} 7_{v i}=y_{i v}\right]=\mu\left(y_{v i} \mid \widetilde{S} 3_{v i}\right) \text {, } \\
& \operatorname{Poss}\left[\widetilde{S} \varepsilon_{\mathrm{i}}=\mathrm{y}_{\mathrm{t}}\right]=\mu\left(\mathrm{y}_{\mathrm{l}} \mid \widetilde{\mathrm{S}} 4_{\mathrm{t}}\right) \text {. }
\end{aligned}
$$

In this paper we do not consider solutions based on the extension principle, because the extension principle solution to equation (1) may not exist, and the extension principle solutions to equations (11a), (11b), (13a) and (13b) will be equal to $\tilde{\mathrm{S}} 1_{\mathrm{t}}, \quad \tilde{\mathrm{S}} 2_{\mathrm{t}}, \quad \tilde{\mathrm{S}} 3_{\mathrm{t} j}$ and $\tilde{\mathrm{S}} 4_{\mathrm{t}}$, respectively. We also do not present solutions based on $\alpha$-cuts and interval arithmetic, because they are essentially only a way for approximate computation.

Consequently, we can give the following four solutions for the fuzzy trajectories of the endogenous variables:

$$
\begin{aligned}
\tilde{S} 1=\bigcup_{t=1}^{T}\left\{t x \tilde{S} 1_{t}\right\}, \tilde{S} 2=\bigcup_{t=1}^{T}\left\{\operatorname{tx} \tilde{S} 2_{t}\right\}, \\
\tilde{S} 3:=\bigcup_{t=1}^{T}\left\{t x \tilde{S} 3_{t}\right\}, \tilde{S} 4=\bigcup_{t=1}^{T}\left\{\operatorname{tx} \tilde{S} 4_{t}\right\} .
\end{aligned}
$$

These solutions are very informative and helpful to economics analysts, but the authorities taking economic decisions usually prefer forecasts to be presented in a simpler form. The problem is to propose a simple prognosis which still provides enough information. Let $S_{\alpha}$ be this informative solution. If $\tilde{S}$ is one of the solutions given in (24) with $\alpha$-cuts

$$
\begin{aligned}
\tilde{S}(\alpha) & =[\underline{\mathrm{y}(\alpha)}, \overline{\mathrm{y}(\alpha)}]=\bigcup_{\mathrm{t}=1}^{\mathrm{T}}\left\{\mathrm{tx} \tilde{\mathrm{S}}_{\mathrm{t}}(\alpha)\right\}= \\
& =\int_{t=1}^{T}\left\{\operatorname { t x } \left[\underline{\left.\mathrm{y}_{\mathrm{t}}(\alpha), \overline{\mathrm{y}_{\mathrm{t}}(\alpha)}\right], 0 \leq \alpha \leq 1,}\right.\right.
\end{aligned}
$$

then define

$$
\mathrm{S}_{\alpha}=\mathrm{H}(\tilde{\mathrm{S}}(\alpha)), 0 \leq \alpha \leq 1, \text { where }
$$




$$
H: \underbrace{I(R)^{n_{1}} x \ldots x I(R)^{n_{1}}}_{T} \rightarrow \underbrace{R^{n_{1}} X \ldots x R^{n_{1}}}_{T},
$$

(I(R) is the set of all real interval numbers). Now for each level of uncertainty there is a crisp solution. We must say that when $\alpha$ increases, the level of uncertainty decreases. The $\mathrm{H}$ can takes different forms. For example, $S_{\alpha}$ can be defined by:

$$
\begin{aligned}
& S_{\alpha}=\bigcup_{t=1}^{T}\left\{\operatorname{tx}_{\alpha}\right\}, 0 \leq \alpha \leq 1, \text { where } \\
& S_{\alpha \mathrm{c}}=\frac{\alpha}{2 \alpha+1} \frac{y_{t}(\alpha)}{2 \alpha+1} y_{t}(1)+\frac{\alpha}{2 \alpha+1} \overline{y_{t}(\alpha)}
\end{aligned}
$$

\section{4: Evaluating the exact solutions}

Now the exact interval $\tilde{\mathrm{S}} 3_{\mathrm{tj}}(\alpha)=\left[\mathrm{y}_{\mathrm{tj}}(\alpha), \overline{\mathrm{y}_{\mathrm{ij}}(\alpha)}\right]$ will be computed. For each $\alpha \in[0,1]$, we consider a nonlinear programme

$$
\begin{array}{ll}
\begin{array}{l}
\text { Minimize (Maximize) } \\
\text { subject to }
\end{array} & \mathrm{y}_{\mathrm{t}}=\mathrm{g}_{\mathrm{y}}\left(\mathrm{r}_{1}, \ldots, \mathrm{r}_{\mathrm{p}}\right) \\
\text { and } & \mathrm{v}_{\mathrm{i}}\left(\mathrm{r}_{1}, \ldots, \mathrm{r}_{\mathrm{p}}\right)=\mathrm{r}_{\mathrm{i}}-\mathrm{r}_{\mathrm{i}}(\alpha) \geq 0, \mathrm{i}=\overline{\mathrm{l}, \mathrm{p}} \\
\mathrm{v}_{\mathrm{p}+\mathrm{i}}\left(\mathrm{r}_{1}, \ldots, \mathrm{r}_{\mathrm{p}}\right)=\mathrm{r}_{\mathrm{i}}-\overline{\mathrm{r}_{\mathrm{i}}(\alpha)} \leq 0, \mathrm{i}=\overline{1, p} .
\end{array}
$$

The Kuhn-Tucker conditions for this problem takes form

$$
\begin{aligned}
& \lambda_{i} \geq 0 \quad\left(\lambda_{i} \leq 0\right), \quad i=\overline{1, p}, \\
& \lambda_{p+i} \leq 0 \quad\left(\lambda_{p+i} \geq 0\right), \quad i=\overline{1, p}, \\
& \frac{\partial g_{t j}\left(r_{1}, \ldots, r_{p}\right)}{\partial r_{i}}-\sum_{w=1}^{2 p} \lambda_{w} \frac{\partial v_{w}\left(r_{1}, \ldots, r_{p}\right)}{\partial r_{i}}=0, \quad i=\overline{1, p}, \\
& \lambda_{w} v_{w}\left(r_{1}, \ldots, r_{p}\right)=0, \quad w=\overline{1,2 p}, \\
& v_{i}\left(r_{1}, \ldots, r_{p}\right) \geq 0, \quad i=\overline{1, p}, \\
& v_{p+i}\left(r_{1}, \ldots, r_{p}\right) \leq 0, \quad i=\overline{1, p},
\end{aligned}
$$

where $\lambda_{1} \geq 0$ and $\lambda_{\mathrm{p+t}} \leq 0 \quad\left(\lambda_{1} \leq 0\right.$ and $\left.\lambda_{\mathrm{p}+1} \geq 0\right)$ correspond to the minimization (maximization problem). As the feasible region is a convex set and all the constraints are linear, the constraint qualification are invariably met and the Kuhn-Tucker conditions [9] are necessary conditions for an extremum. They will be also sufficient for a minimum (maximum) if the objective function $\mathrm{g}_{\mathrm{y}}\left(\mathrm{r}_{1}, \ldots, \mathrm{r}_{\mathrm{p}}\right)$ is convex (concave) in the feasible region.

Therefore, we can proceed in the following way:

$$
\begin{aligned}
& \text { 1. Evaluate } \frac{\partial^{2} g_{t j}\left(r_{1}, \ldots, r_{p}\right)}{\partial r_{i}}, i=\overline{1, p} \text {. } \\
& \text { 2. If } \frac{\partial^{2} g_{t j}\left(r_{1}, \ldots, r_{p}\right)}{\partial r_{1}^{2}} \geq 0 \text { for all } r \in \tilde{R}(\alpha) \text {, } i=\overline{1, p} \text {, then }
\end{aligned}
$$

2.1. find $y_{t_{j}}(\alpha)$ by solving the minimization problem.

2.2. Evaluate $g_{i j}\left(r_{1}, \ldots, r_{p}\right)$ in both point $\left(\underline{r_{1}(\alpha)}, \ldots, \underline{\left.r_{p}(\alpha)\right)}\right)$ and point $\left(\overline{r_{1}(\alpha)}, \ldots, \overline{r_{p}(\alpha)}\right)$.

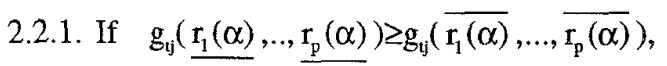
then $\overline{y_{t j}(\alpha)}=g_{v j}\left(r_{1}(\alpha), \ldots, r_{p}(\alpha)\right)$.

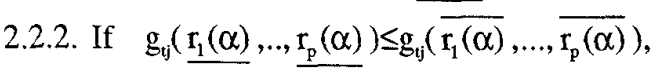
then $\overline{\mathrm{y}_{\mathrm{tj}}(\alpha)}=\mathrm{g}_{\mathrm{ij}}\left(\overline{\mathrm{r}_{1}(\alpha)}, \ldots, \overline{\mathrm{r}_{\mathrm{p}}(\alpha)}\right)$.

3. If $\frac{\partial^{2} g_{i j}\left(r_{1}, \ldots, r_{p}\right)}{\partial r_{i}^{2}} \leq 0$ for all $r \in \tilde{R}(\alpha), i=\overline{1, p}$, then

3.1. solve the maximization problem. Its solution is equal to $\overline{\mathrm{y}_{\mathrm{tj}}(\alpha)}$.

3.2. Evaluate $g_{i j}\left(r_{1}, \ldots, r_{p}\right)$ in both point $\left(\underline{r_{1}(\alpha)}, \ldots, r_{p}(\alpha)\right)$ and point $\left(\overline{r_{1}(\alpha)}, \ldots, \overline{r_{p}(\alpha)}\right)$.

3.2.1. If $\mathrm{g}_{\mathrm{ij}}\left(\mathrm{r}_{1}(\alpha), \ldots, \mathrm{r}_{\mathrm{p}}(\alpha)\right) \leq \mathrm{g}_{\mathrm{i}}\left(\overline{\mathrm{r}_{1}(\alpha)}, \ldots, \overline{\mathrm{r}_{\mathrm{p}}(\alpha)}\right)$, then $\overline{y_{t j}(\alpha)}=g_{i j}\left(r_{1}(\alpha), \ldots, r_{p}(\alpha)\right)$.

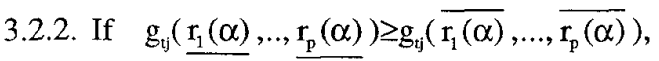
then $\overline{y_{t j}(\alpha)}=g_{i j}\left(\overline{r_{1}(\alpha)}, \ldots, \overline{r_{p}(\alpha)}\right)$.

4. If the sign of $\frac{\partial^{2} \mathrm{~g}_{\mathrm{t} j}\left(\mathrm{r}_{1}, \ldots, \mathrm{r}_{\mathrm{p}}\right)}{\partial \mathrm{r}_{\mathrm{i}}^{2}}$ changes in the feasible region, then the exact interval $\tilde{\mathrm{S}} 3_{\mathrm{rj}}(\alpha)$ can not be find. We have to apply interval arithmetic and compute an approximate solution.

Example. We will consider the simple economic model below.

$$
\begin{aligned}
& \mathrm{C}_{\mathrm{t}}=\mathrm{r}_{1} \mathrm{C}_{\mathrm{t}-1}+\mathrm{r}_{2} \mathrm{Y}_{\mathrm{t}}+\mathrm{r}_{3} \mathrm{Y}_{\mathrm{t}-1} \\
& \mathrm{I}_{\mathrm{t}}=\mathrm{r}_{4} \mathrm{I}_{\mathrm{t}-1}+\mathrm{r}_{5} \mathrm{Y}_{\mathrm{t}-2} \\
& \mathrm{Y}_{\mathrm{t}}=\mathrm{C}_{\mathrm{t}}+\mathrm{I}_{\mathrm{t}}+\mathrm{G}_{\mathrm{t}-2},
\end{aligned}
$$

where consumption $\mathrm{C}$, total investment $\mathrm{I}$, and national income $\mathrm{Y}$ are endogenous variables and government expenditures $G$ is a control variable. We need to define only two new variables, $Y 1_{t}=Y_{t-1}$ and $G 1_{t}=G_{t-1}$, to present this model as a quasi first-order system:

$$
\begin{aligned}
{\left[\begin{array}{c}
C_{t} \\
I_{t} \\
Y_{t} \\
Y_{t} \\
G 1_{t}
\end{array}\right] } & =\left[\begin{array}{ccccc}
1 & 0 & -r_{2} & 0 & 0 \\
0 & 1 & 0 & 0 & 0 \\
-1 & -1 & 1 & 0 & 0 \\
0 & 0 & 0 & 1 & 0 \\
0 & 0 & 0 & 0 & 1
\end{array}\right]^{-1}\left[\begin{array}{ccccc}
r_{1} & 0 & r_{3} & 0 & 0 \\
0 & r_{4} & 0 & r_{5} & 0 \\
0 & 0 & 0 & 0 & 1 \\
0 & 0 & 1 & 0 & 0 \\
0 & 0 & 0 & 0 & 0
\end{array}\right]\left[\begin{array}{c}
C_{t-1} \\
I_{t-1} \\
Y_{t-1} \\
Y_{t_{t-1}} \\
G 1_{t-1}
\end{array}\right] \\
& +\left[\begin{array}{ccccc}
1 & 1 & 1-r_{2} & 1 & 1 \\
1 & 1 & 1 & 1 & 1 \\
0 & 0 & 1 & 1 & 1 \\
1 & 1 & 1 & 1 & 1 \\
1 & 1 & 1 & 1 & 1
\end{array}\right]^{-1}\left[\begin{array}{c}
0 \\
0 \\
0 \\
0 \\
G_{t-1}
\end{array}\right]
\end{aligned}
$$

The initial data are

$$
\mathrm{G}_{-1}=52.5, \mathrm{G}_{0}=52.5, \mathrm{G}_{1}=52.8, \mathrm{G}_{2}=53.1, \mathrm{C}_{0}=286.7,
$$




$$
\mathrm{I}_{0}=47.7, \mathrm{Y}_{-1}=385.8, \mathrm{Y}_{0}=386.6 \text {. }
$$

Let us now evaluate the exact fuzzy trajectory of $C_{t}$. First define functions $g_{t 1}\left(r_{1}, \ldots, r_{s}\right), t=\overline{1,3}$ :

$$
\begin{aligned}
& \mathrm{g}_{11}=\left(286.7 \mathrm{r}_{1}+52.5 \mathrm{r}_{2}+386.6 \mathrm{r}_{3}+47.7 \mathrm{r}_{2} \mathrm{r}_{4}+385.8 \mathrm{r}_{2} \mathrm{r}_{5}\right) /\left(1-\mathrm{r}_{2}\right) \text {, } \\
& \mathrm{g}_{21}=\left(52.5 \mathrm{r}_{2}+47.7 \mathrm{r}_{2} \mathrm{r}_{4}{ }^{2}+386.6 \mathrm{r}_{2} \mathrm{r}_{5}+385.8 \mathrm{r}_{2} \mathrm{r}_{4} \mathrm{r}_{5}\right) /\left(1-\mathrm{r}_{2}\right)+ \\
& +\left(286.7 r_{1}^{2}+52.5 r_{1} r_{2}+52.5 r_{3}+673.3 r_{1} r_{3}+386.6 r_{3}^{2}+\right. \\
& \left.+47.7 r_{1} r_{2} r_{4}+47.7 r_{3} r_{4}+385.8 r_{1} r_{2} r_{5}+385.8 r_{3} r_{5}\right) /\left(1-r_{2}\right)^{2} \\
& g_{31}=\left(52.8 r_{2}+47.7 r_{2} r_{4}^{3}+386.6 r_{2} r_{4} r_{5}+385.8 r_{2} r_{4}{ }_{2} r_{5}\right) /\left(1-r_{2}\right)+ \\
& +\left(52.5 r_{1} r_{2}+52.5 r_{3}+47.7 r_{3}{ }^{2} r_{4}+47.7 r_{1} r_{2} r_{4}{ }^{2}+47.7 r_{3} r_{4}{ }^{2}+\right. \\
& +52.5 r_{2} r_{5}+673.3 r_{1} r_{2} r_{5}+386.6 r_{3} r_{5}+386.6 r_{2} r_{3} r_{5}+47.7 r_{2} r_{4} r_{5}+ \\
& \left.+385.8 r_{1} r_{2} r_{4} r_{5}+385.8 r_{3} r_{4} r_{5}+385.8 r_{2} r_{5}{ }^{2}\right) /\left(1-r_{2}\right)^{2}+\left(286.7 r_{1}{ }^{3}+\right. \\
& +52.5 r_{1}{ }^{2} r_{2}+52.5 r_{1} r_{3}+960 r_{1}^{2} r_{3}+52.5 r_{1} r_{2} r_{3}+52.5 r_{3}^{2}+ \\
& +1059.9 r_{1} r_{3}^{2}+386.6 r_{3}^{3}+47.7 r_{1}^{2} r_{2} r_{4}+47.7 r_{1} r_{3} r_{4}+47.7 r_{1} r_{2} r_{3} r_{4} \\
& +47.7 r_{3}^{2} r_{4}+385.8 r_{1}^{2} r_{2} r_{5}+385.8 r_{1} r_{3} r_{5}+385.8 r_{1} r_{2} r_{3} r_{5}+ \\
& \left.+385.8 r_{3}{ }^{2} r_{5}\right) /\left(1-r_{2}\right)^{3}
\end{aligned}
$$

One may check that $\frac{\partial^{2} \mathrm{~g}_{\mathrm{t} 1}\left(\mathrm{r}_{1}, \ldots, \mathrm{r}_{5}\right)}{\partial \mathrm{r}_{\mathrm{i}}^{2}} \geq 0, \mathrm{i}=\overline{1,5}, \mathrm{t}=\overline{1,3}$, if

$r_{1} \geq 0, \quad 1 \geq r_{2} \geq 0, \quad r_{3} \geq 0, \quad r_{4} \geq 0, \quad$ and $r_{5} \geq 0$, which does not contradict to their economic meaning.

Let $\widetilde{\mathrm{R}}_{1}=(0.7752 / 0.9690 / 1.3566)$,

$\tilde{\mathrm{R}}_{2}=(0.01896 / 0.0237 / 0.03318)$,

$\tilde{\mathrm{R}}_{3}=(0.00512 / 0.0064 / 0.00896)$,

$\tilde{\mathbf{R}}_{4}=(0.81208 / 1.0151 / 1.42114)$,

$\tilde{R}_{5}=(0.00008 / 0.0001 / 0.00014)$.

The algorithm given above will produce

\begin{tabular}{l|l|l|l|l}
$\alpha$ & 0 & 0.3 & 0.6 & 1 \\
\hline$\underline{C_{1}(\alpha)}$ & 230.327 & 248.021 & 265.775 & 289.541 \\
\hline$\overline{\overline{C_{1}(\alpha)}}$ & 409.998 & 373.574 & 337.397 & 289.541 \\
\hline$C_{1 \alpha}$ & 289.541 & 297.512 & 315.912 & 289.541 \\
\hline$\underline{C_{2}(\alpha)}$ & 185.302 & 214.759 & 265.775 & 292.406 \\
\hline$\overline{\overline{C_{2}(\alpha)}}$ & 585.318 & 486.136 & 337.397 & 292.406 \\
\hline$C_{2 \alpha}$ & 292.406 & 314.171 & 297.413 & 292.406 \\
\hline$\underline{C_{3}(\alpha)}$ & 149.344 & 186.159 & 228.743 & 295.301 \\
\hline$\overline{C_{3}(\alpha)}$ & 834.624 & 631.996 & 466.185 & 295.301 \\
\hline$C_{3 \alpha}$ & 295.301 & 361.237 & 323.754 & 295.301
\end{tabular}

The informative crisp solution is also shown in the table.

We have used the computing environment MATHEMATICA and the Optimization Toolbox of package MATLAB WTTH SIMULINK to realize the algorithm.

By analogy, a computing procedure for $\widetilde{\mathrm{S}} 1_{\mathrm{ij}}$ can be derived.

\section{3: Conclusions}

Solving systems of fuzzy difference equations, one can study economic systems dynamics in case of uncertainty. Some methods for evaluating the trajectories of economic variables are presented in the paper. An algorithm for computing the exact $\alpha$-cuts of the derived solutions is proposed. Further investigations to practical applications will be provided. An extension of the algorithm to solutions $\widetilde{S} 4_{t}$ and $\widetilde{S} 2_{t}$. is also under consideration.

\section{4: References}

1. J.J. Buckley, The fuzzy mathematics of finance, Fuzzy Sets and Systems 21 (1987) 257-273.

2. J.J. Buckey and Y. Qu, Solving linear and quadratic fuzzy equations, Fuzzy Sets and Systems 38 (1990) 43-59.

3. J.J. Buckley and Y. Qu, Solving fuzzy equations: A new solution concept, Fuzzy sets and Systems 39 (1991) 291301.

4. J.J. Buckley and Y. Qu, Solving systems of linear fuzzy equations, Fuzzy Sets and Systems 43 (1991) 33-43.

5. J.J. Buckley, Solving fuzzy equations in economics and finance, Fuzzy Sets and Systems 48 (1992) 289-296.

6. J.J. Buckley, Solving fuzzy equations, Fuzzy Sets and Systems 50 (1992) 1-14.

7. J.J. Buckley and Y. Qu, Fuzzy differential equations: New Solutions, J. Math. Anal. Appl. Under review.

8. J.J. Buckley, Solving fuzzy equations, J. Math. Anal. Appl. Under review.

9. A.C. Chiang, Fundamental methods of Mathematical Economics (McGraw-Hill, Singapore, 1984).

10. G.C. Chow, Econometrics (McGraw-Hill, Singapore, 1988).

11. D.Dubois and H. Prade, Operations on fuzzy numbers, Internat. J. System Science 9 (1978) 613-626.

12. D. Dubois and H. Prade, Fuzzy real algebra: Some results, Fuzzy Sets and Systems 2 (1979) 327-348.

13. G.I. Gatev, Robust controllability and observability of linear systems under interval parametric uncertainty, Proceedings of National Conference in Automatics (Sofia, BULGARIA, 1995) 67-70.

14. O. Kaleva, Fuzzy differential equations, Fuzzy Sets and Systems 24 (1987) 301-317.

15 . W. Pedrycz, On solution of fuzzy functional equations, $J$. Math. Anal. Appl. 123 (1987) 589-604.

16. R.S. Pirdyck, Optimal Planning for Economic Stabilization. The Application of Control Theory to Stabilization Policy. (North-Holland, Amsterdam 1973).

17. S. Seikkala, On the fuzzy initial value problem, Fuzzy Sets and Systems 24 (1987) 319-330.

18. A.I. Serguieva and G.I. Gatev, Basic models of mathematical economics, Economic Thought 5 (1994) 91109.

19. A.I. Serguieva, Macroeconomic modelling and optimal trajectories determination, Automatica \&Informatics To be published. 